\title{
A high incidence of WT1 abnormality in bilateral Wilms tumours in Japan, and the penetrance rates in children with WT1 germline mutation
}

 \\ A Yoneda ${ }^{2}$, Y Ohtsuka ${ }^{2}$, T Taguchi $^{2}$ and M Fukuzawa ${ }^{2}$ \\ ${ }^{1}$ Department of Cancer Diagnosis, Research Institute for Clinical Oncology, Saitama Cancer Center, Ina, Saitama 362-0806, Japan; \\ ${ }^{2}$ Japan Wilms Tumor Study Group (JWiTS), Itabashi-Ku, Tokyo 173-8610, Japan and ${ }^{3}$ Division of Cancer Genomics, National \\ Cancer Center Research Institute, Chuo-Ku, Tokyo 104-0045, Japan
}

Background: Bilateral Wilms tumours (BWTs) occur by germline mutation of various predisposing genes; one of which is WT1 whose abnormality was reported in 17-38\% of BWTs in Caucasians, whereas no such studies have been conducted in East-Asians. Carriers with WT1 mutations are increasing because of improved survival.

Methods: Statuses of WT1 and IGF2 were examined in 45 BWTs from 31 patients with WT1 sequencing and SNP array-based genomic analyses. The penetrance rates were estimated in WT1-mutant familial Wilms tumours collected from the present and previous studies.

Results: We detected WT1 abnormalities in 25 (81\%) of 31 patients and two families, which were included in the penetrance rate analysis of familial Wilms tumour. Of 35 BWTs from the 25 patients, 31 had small homozygous WT1 mutations and uniparental disomy of IGF2, while 4 had large 11 p13 deletions with the retention of $11 \mathrm{p}$ heterozygosity. The penetrance rate was $100 \%$ if children inherited small WT1 mutations from their fathers, and $67 \%$ if inherited the mutations from their mothers, or inherited or had de novo 11 p13 deletions irrespective of parental origin $(P=0.057)$.

Conclusions: The high incidence of WT1 abnormalities in Japanese BWTs sharply contrasts with the lower incidence in Caucasian counterparts, and the penetrance rates should be clarified for genetic counselling of survivors with WT1 mutations.

Wilms tumour (WT; OMIM 194070) arises from the developmental kidney (Rivera and Haber, 2005). Wilms tumour and retinoblastoma are typical embryonal tumours. The WT1 gene was altered in $<25 \%$ of sporadic WTs (Haruta et al, 2012), whereas the $R B 1$ gene was shown to be altered in $>90 \%$ of hereditary and non-hereditary retinoblastoma (Leiderman et al, 2007), indicating genetic heterogeneity and homogeneity of WT and retinoblastoma, respectively. Bilateral WT is thought to be hereditary, and the germinal mutation of WT1 located in $11 \mathrm{p} 13$ and alterations of
11 p15 were reported in $17-38 \%$ and $55 \%$, respectively, of bilateral WTs in the series reported from USA, UK and Australia (Huff, 1998; Scott et al, 2012; Hu et al, 2013). Carriers with WT1 mutations are now increasing because multidisciplinary therapies have improved the survival rates of patients with bilateral WTs and those with a unilateral WT (UWT) with a WT1 germline mutation (Royer-Pokora et al, 2008; Hu et al, 2013). The penetrance rates of WT1-mutant familial WT (FWT) are needed for genetic counselling of WT survivors. However, investigators have never examined 
the incidence of WT1 and 11p15 abnormalities in bilateral WTs of East Asian children, and have not yet tried to estimate the penetrance rates of WT1-mutant FWT.

WT1 is a multifunctional protein that acts as a transcriptional activator or repressor, is predominantly expressed in the embryonic kidney, and plays a pivotal role in its development (Huff, 2011). Insulin-like growth factor II (IGF2; OMIM 147470) is an imprinted gene expressed by the paternal allele, and encodes a foetal polypeptide growth factor (Foulstone et al, 2005). In contrast, WT1 is biallelically expressed in normal foetal tissues and WTs (Little et al, 1992). The loss of heterozygosity (LOH) and loss of imprinting (LOI) of IGF2 have been reported in 30-40\% and $30-70 \%$ of sporadic WTs, respectively, and these alterations cause the overexpression of IGF2, which is involved in Wilms tumorigenesis (Schroeder et al, 1987; Ravenel et al, 2001; Haruta et al, 2008).

Both WT1 and IGF2 genes are located on the short arm of chromosome 11 (11p) and uniparental disomy (UPD) on 11p, involving either the region limited to $11 \mathrm{p} 15$ or that including both $11 \mathrm{p} 15$ and $11 \mathrm{p} 13$, is regularly accompanied by maternal allele loss and paternal allele duplication (Schroeder et al, 1987). We previously reported that small homozygous WT1 mutations and paternal UPD (pUPD) of 11p occurred in one-third of unilateral and bilateral WTs with various WT1 abnormalities (Haruta et al, 2008). Based on these genetic findings of human WT, Hu et al (2011) showed that the combined occurrence of the upregulation of Igf2 and ablation of Wt1 resulted in WT in transgenic Wt1-Igf2 mice; however, the upregulation of Igf2 or ablation of $W t 1$ by themselves did not lead to malignant tumours .

The inheritance of WT1 mutations have been poorly studied in FWTs, and only 13 hereditary WT families with WT1 abnormalities have been described in the literature (Yunis and Ramsay, 1980; Kousseff and Agatucci, 1981; Nakagome et al, 1984; Lavedan et al, 1989; Pelletier et al, 1991; Kaplinsky et al, 1996; Jeanpierre et al, 1998; Pritchard-Jones et al, 2000; Shibata et al, 2002; Zirn et al, 2005; Regev et al, 2008; Fencl et al, 2012; Melchionda et al, 2013). In addition, the parental origins of de novo small WT1 mutations and large $11 \mathrm{p} 13$ deletions encompassing WT1 were reported previously in two and eight individuals, respectively (Huff et al, 1990; Nordenskjold et al, 1994). The aim of the present study was to determine the incidence rates of WT1 and IGF2 abnormalities in bilateral WTs in Japanese children, and was to compare the results with those reported in bilateral WTs of Caucasian children. In addition, we summarised the present and previous findings on the penetrance rate for children who inherited various types of $W T 1$ abnormalities from their fathers or mothers, or had de novo WT1 (DNWT1) abnormalities that occurred in the paternal or maternal germ cell, and tried to clarify whether parental inheritance and WT1 abnormality types may affect the penetrance rate of hereditary WT.

\section{MATERIALS AND METHODS}

Patients and samples. Forty-five tumour samples were available from 31 Japanese infants or children with bilateral WT, ranging in age between 2 and 26 months, who underwent surgery or biopsy between August 1996 and 2011 (Table 1); 11 of the 45 tumours and 7 of the 31 patients were described in a previous series of patients with WT1-mutant WT (Shibata et al, 2002; Haruta et al, 2008). In one of the seven patients, data on the $11 \mathrm{p} 15$ status was added and shown as Bilateral Wilms tumour 23 (BWT23) (Table 1; Shibata et al, 2002). In addition, five patients, including one with UWT of a DNWT1 mutation (UWTG1), one with familial and UWTG2, one with Wilms tumour-aniridia-genitourinary malformation-mental retardation (WAGR) syndrome-associated UWTG8 and two with sporadic and UWTS1 and 5 were incorporated into our previous study for a comparison of the data with those of WT1-mutant bilateral WTs (Table 2). Normal tissue samples were obtained from either peripheral blood $(\mathrm{PB})$ or normal renal tissue adjacent to the tumour from the same patients. Tumours were staged according to the National Wilms Tumor Study Group (NWTS) staging system and most patients were treated according to the NWTS protocols (D’Angio et al, 1989; Oue et al, 2009). Malformations found in patients with bilateral WT are listed in Table 1. None of the patients in the present study showed hemihypertrophy or malformations associated with Beckwith-Wiedemann syndrome (BWS; OMIM\#130650). One (BWT9) died of the disease, another (BWT27) with premature chromatid separation (PCS) syndrome died of infection (Matsuura et al, 2006) and 29 were alive at the last follow-up.

This study was approved by the Ethics Committee at Saitama Cancer Center, and written informed consent was obtained from parents for samples from the Japan Wilms Tumor Study Group (JWiTS; Oue et al, 2009). Since written informed consent was not obtained in a subset of patients collected before 2001, identifying information was removed prior to their analysis, in accordance with the Ethical Guidelines for Clinical Research enacted by the Japanese Government. The Ethics Committee approved the waiver of written informed consent for the latter samples.

Histological examination. The diagnosis of WT was made in all 45 tumours, with routine haematoxylin and eosin-stained pathology slides by pathologists at each institution or the JWiTS pathology panel according to the classification proposed by the Japanese Society of Pathology (The committee on histological classification of childhood tumors, 2008). In addition, a pathological review of 29 tissue specimens was performed by the JWiTS pathology panel.

Analysis of WT1 and allelic loss on 11p and 11q. Copy number and $\mathrm{LOH}$ analysis using single-nucleotide polymorphisms (SNP) arrays, Affymetrix Mapping 50K-Xba and 250K-Nsp arrays (Affymetrix, Santa Clara, CA, USA) was conducted as described previously (Haruta et al, 2008). Copy numbers and LOH were calculated using CNAG and AsCNAR programmes with paired or anonymous references as controls (Nannya et al, 2005; Yamamoto et al, 2007). Gross WT1 deletions were analysed by Southern blotting using a WT1 cDNA probe and BCL1 in chromosome band $11 \mathrm{q} 13$, or by SNP arrays or the multiplex ligation-dependent probe amplification (MLPA) method (Salsa MLPA kit, MRC-Holland, Amsterdam, the Netherlands). To detect small WT1 mutations, defined as missense, nonsense, frame-shift or splice-site mutations, all coding exons including flanking intronic sequences of WT1 were amplified from genomic DNA by PCR, and PCR products were directly sequenced with the BigDye Terminator v3.1 Cycle Sequencing Kit (Applied Biosystems, Foster City, CA, USA).

COBRA of the CTCF6 site at H19-DMR or MS-MLPA of the IC1 (H19-DMR) and IC2 (KvDMR) regions. We determined the methylation status of $11 \mathrm{p} 15$ region in tumour and $\mathrm{PB}$ samples by combined bisulfite restriction assay (COBRA; Watanabe et al, 2006) and/or methylation specific (MS)-MLPA (Salsa MS-MLPA kit, ME030BWS/SRS) assay. Combined bisulfite restriction assay of CTCF6 at H19-differentially methylated region (H19-DMR) showed that the mean methylation percentage \pm 2 s.d. of five normal kidney and two PB samples was $53.6 \pm 5.6 \%$, and we defined more than the mean percentage +2 s.d. as the hypermethylated state. Methylation specific-MLPA analysis was used to detect the methylation status of the IC1 (H19-DMR) and IC2 (KvDMR) regions. The methylation statuses were defined according to the manufacturer's instructions.

Statistical analysis. Differences in the incidence of clinical and genetic characteristics between any two genetic subtypes of 




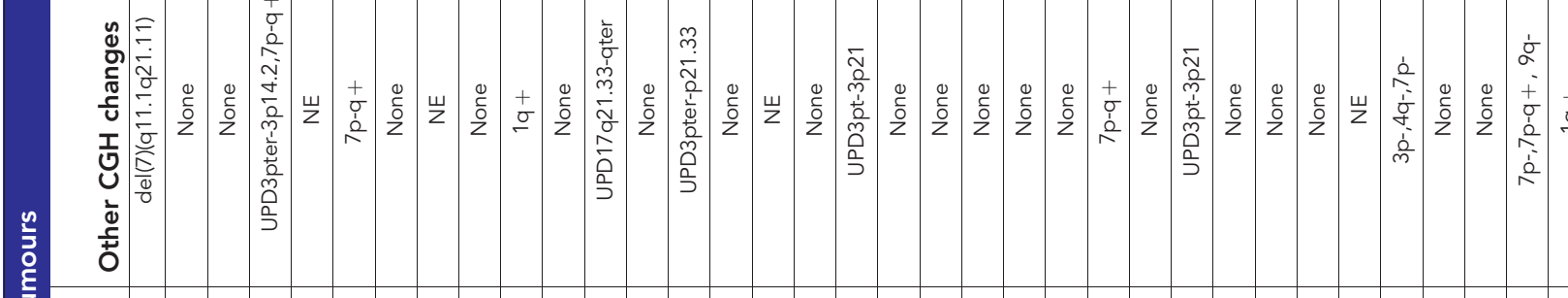

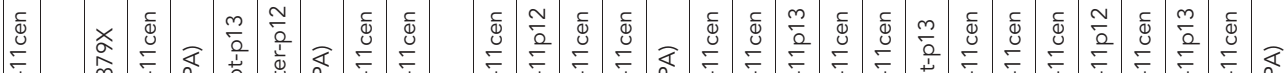
音



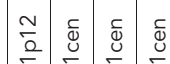



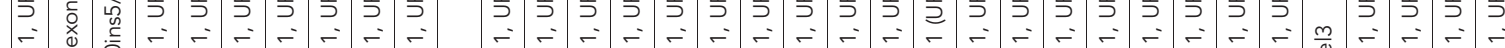



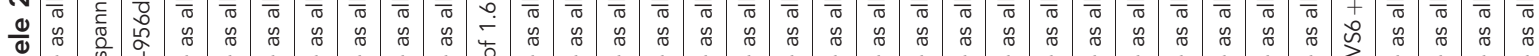



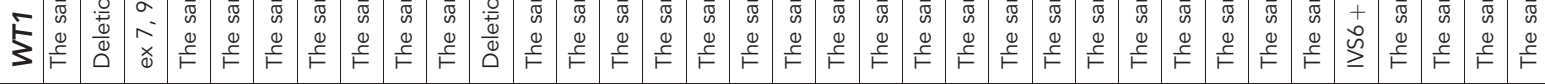



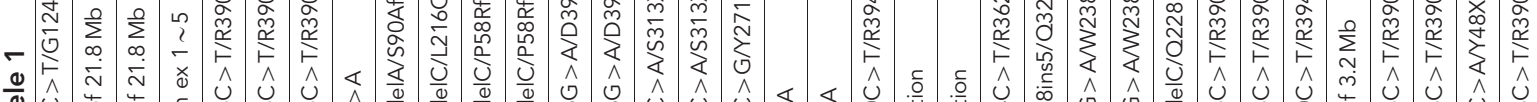

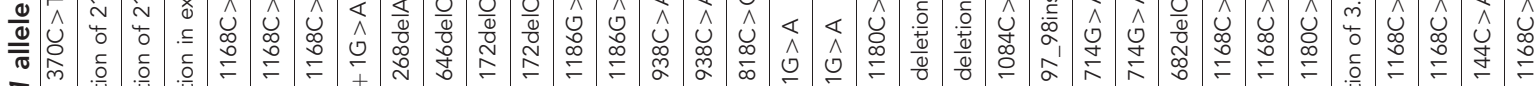

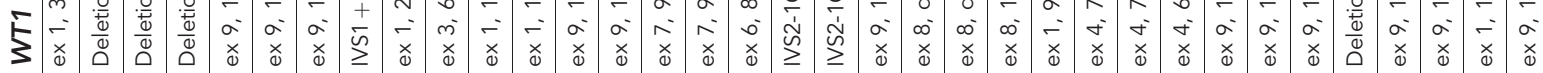

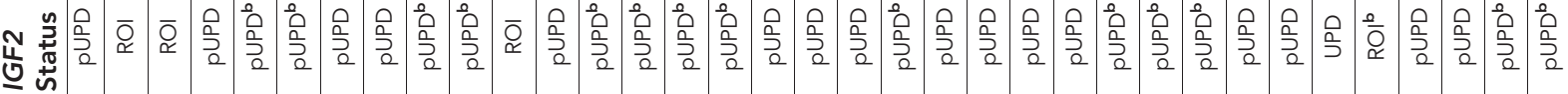

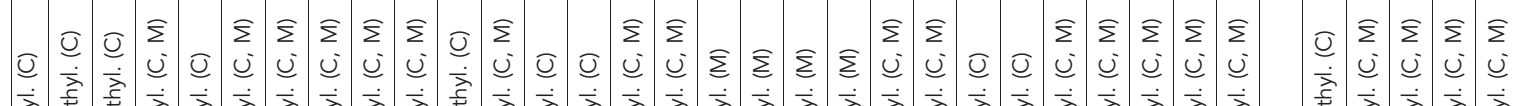

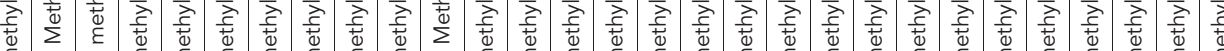

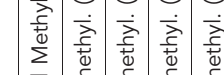

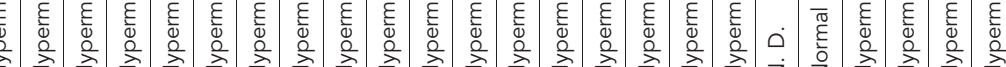

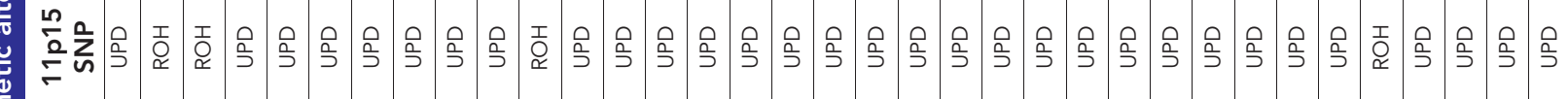

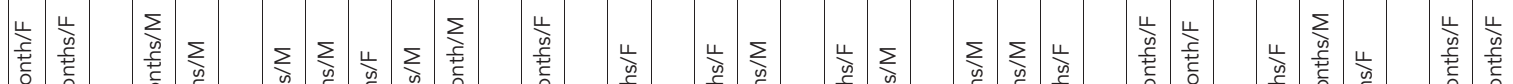

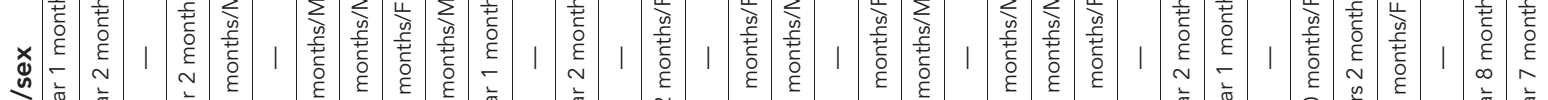

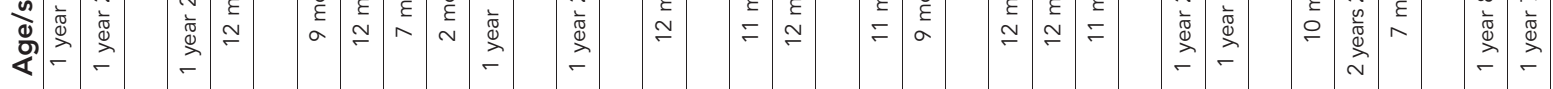




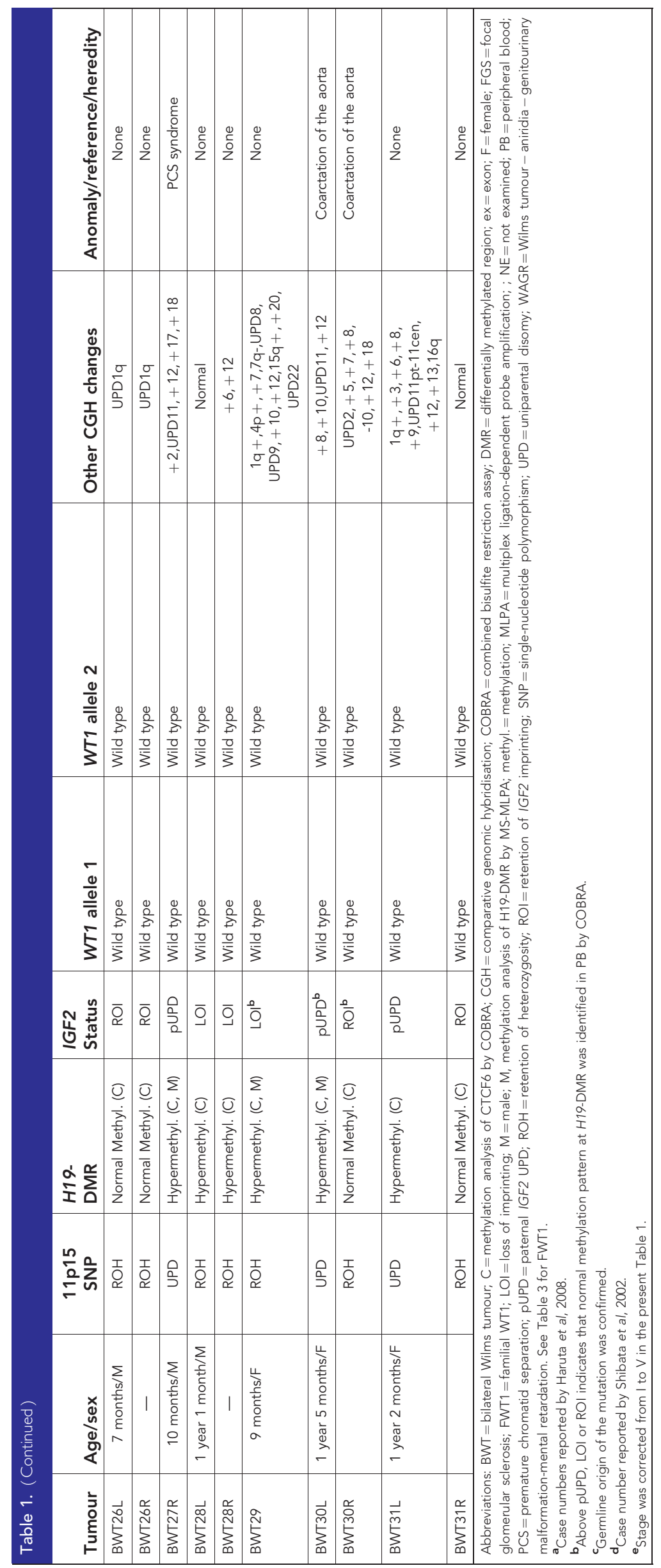




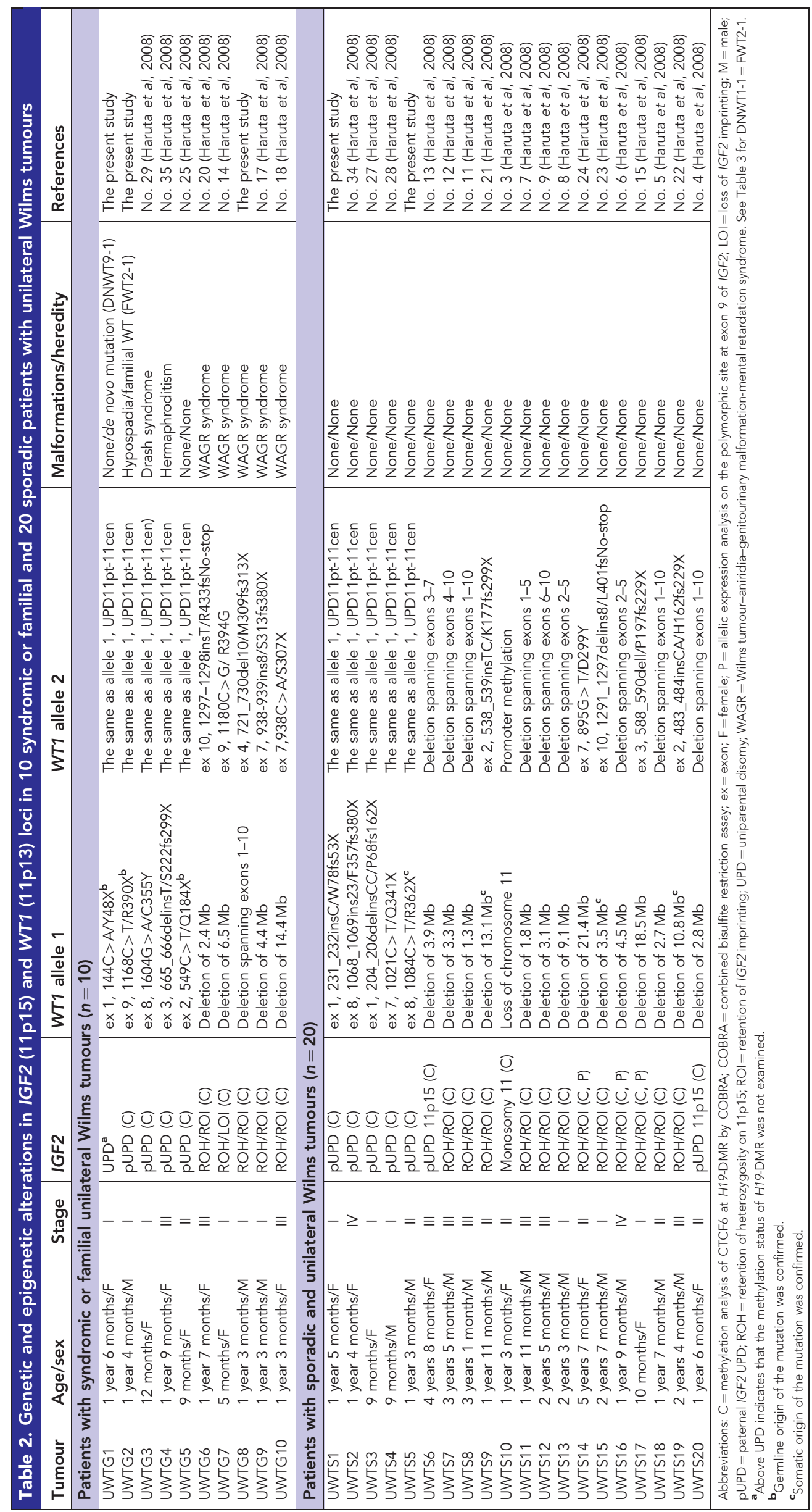


tumours were examined by the $\chi^{2}$ or Fisher's exact test. $P<0.05$ (two-sided) was considered statistically significant. The Student's $t$-test or Mann-Whitney test was used to compare mean ages between patients with WT1-mutant bilateral WT and those with WT1-mutant sporadic and UWT, between patients with sporadic and UWT with a small WT1 mutation and those with sporadic and UWT with a large WT1 deletion, or between patients with paternal inheritance of a small WT1 mutation and those with maternal inheritance of a small WT1 mutation.

\section{RESULTS}

Bilateral WT1-mutant WTs with or without pUPD on 11p. Of 45 bilateral tumours from 31 patients, 35 tumours from 25 (81\%) patients had WT1 abnormalities; 30 tumours from 21 patients showed small mutations in 1 WT1 allele and the same small mutation in the other WT1 allele, caused by UPD on 11p (Table 1). One tumour (BWT3R) with deletion flanking exons 1-5 also had UPD on $11 \mathrm{p}$, and was added to the above 30 tumours because of the small deletion. Combined bisulfite restriction assay and/or MSMLPA identified hypermethylation of H19-DMR, which indicated the paternal origin of IGF2 UPD in all 31 tumours except 1 whose tumour DNA was not available (BWT21R). The remaining four tumours from three patients had large deletions encompassing WT1 in one WT1 allele and a frame-shift or splice-site mutation (three tumours; BWT2R, 9L and 22R) or a small deletion spanning exons 4-9 (one tumour; BWT2L) in the other WT1 allele. All four tumours had the retention of heterozygosity $(\mathrm{ROH})$ on $11 \mathrm{p}$, and had normally methylated CTCF6 at H19-DMR, indicating retention of IGF2 imprinting (ROI). The methylation status of CTCF6 at H19-DMR in PB was examined in 13 of the 25 patients. All 13 patients showed the normal methylation in $\mathrm{PB}$, indicating somatic origin of UPD on 11p15.

WT1-mutant UWTs with or without pUPD on 11p. To compare WT1 and IGF2 statuses between 35 WT1-mutant bilateral WTs and 10 WT1-mutant syndromic or familial UWTs or 20 WT1mutant sporadic and UWTs, we combined our published and unpublished data on WT1-mutant WTs and presented them in Table 2. One (BWT21R) of the 35 WTs and one (UWTG1) of the 10 WTs, in which 11p UPD was identified by SNP array but methylation status of H19-DMR was not examined, were included in each group of tumours with small WT1 mutation and PUPD of IGF2 because all 30 WT1-mutant bilateral WTs with 11p UPD examined in the present study showed the hypermethylation indicating paternal 11p UPD, and the previous study indicated loss of maternal $11 \mathrm{p}$ allele in WTs with $11 \mathrm{p} \mathrm{LOH}$ (Schroeder et al, 1987). Of the 10 patients, 5 (UWTG1-5) had small homozygous WT1 mutations and pUPD on 11p, whereas 5 (UWTG6-10) associated with WAGR syndrome had large deletions in 1 WT1 allele and small mutations in the other WT1 allele with IGF2 ROH/ ROI in the tumours (Table 2). Of the 20 patients, 5 (UWTS1-5) had small homozygous WT1 mutations and pUPD on whole 11p in the tumours, whereas none of the remaining 15 (UWTS6-15) had the small WT1 mutations and pUPD on $11 \mathrm{p} ; 12$ had IGF2 ROI, 2 had pUPD limited to the 11 p15 region and 1 had monosomy 11 of paternal origin in the tumours (Table 2). Thus, a homozygous WT1 mutation with pUPD on 11p was more frequent in 35 WT1-mutant bilateral WTs than in 10 WT1-mutant syndromic or familial UWTs $(P=0.017)$ or 20 WT1-mutant sporadic and UWTs $(P=3.0 \mathrm{E}-06)$.

When we analysed the 3 groups of patients with WT1-mutant WTs, the mean age of 25 patients with bilateral WT was 12.4 months, that of 10 patients with syndromic or familial and UWT was 14.3 months and that of 20 patients with sporadic UWT was 25.6 months. The 25 and 10 patients were younger than the
20 patients, respectively $(P=0.001$ and $P=0.006)$, whereas no difference in age was found between the 25 and 10 patients $(P=0.286)$. When we selected the 20 patients with sporadic and UWTs, the mean age of 5 patients with homozygous WT1 mutations and paternal 11p UPD was 13.2 months and that of 15 patients with large deletions encompassing WT1 with or without pUPD limited to the 11 p15 region in the tumours was 29.7 months. The 5 patients with homozygous WT1 mutations and pUPD on $11 \mathrm{p}$ were younger than the 15 patients with large $11 \mathrm{p} 13$ deletions $(P=0.002)$.

WT1-wild-type bilateral WTs and the IGF2 status. Ten bilateral tumours from six patients had wild-type WT1; six tumours had +12 , and 2 had $1 \mathrm{q}+,+6,+8$. or pUPD of whole chromosome 11 and one had pUPD of 11p (Table 1). None of the six patients showed characteristics of BWS. Single-nucleotide polymorphisms analysis and COBRA of CTCF6 at H19-DMR and/or MS-MLPA revealed PUPD on 11p or whole chromosome 11 in three tumours, ROI of IGF2 in four and LOI of IGF2 in three (Table 1). Of three tumours with pUPD on $11 \mathrm{p}$ or whole chromosome 11, the corresponding $\mathrm{PB}$ showed normal methylation at H19-DMR in one (BWT30L) and was not available in two; in one of the two, the contralateral tumour had ROH/ROI (BWT31R), denying the constitutional 11p15 UPD (BWT31L). Of three tumours with LOI of IGF2, the corresponding PB showed normal methylation at H19DMR in one (BWT29) and was not available in two bilateral WTs (BWT28L, 28R) from one patient, not denying the possibility of constitutional hypermethylation of maternal H19-DMR (Table 1).

Of 27 tumours, whose methylation status at IC2 was examined by MS-MLPA, 26 and 1 showed hypomethylation and normal methylation, respectively; the results were consistent with pUPD and LOI of $11 \mathrm{p} 15$, respectively.

Histology of bilateral and FWTs. Of 29 WT1-mutant bilateral WTs, which were available for pathological review, 25 and 4 tissue specimens were obtained before and after chemotherapy, respectively. Of the 25 tumours, 12 were classified as the mesenchymal type; 4 and 2 of the 12 also had intra-lobar nephrogenic rests (ILNR) and foetal rhabdomyomatous nephroblastoma, respectively, 11 were classified as the mixed type; 1 also had ILNR, 1 was classified as nephroblastoma with ILNR and 1 was classified as ILNR only. Of 4 specimens obtained after chemotherapy, 3 were classified as the mesenchymal type; one also had ILNR, and one as nephroblastoma with ILNR.

Of seven WT1-wild-type bilateral WTs from six patients, which were available for pathological review, five and two specimens were obtained before and after chemotherapy, respectively. Of the five tumours, two (BWT28, and 29) were classified as the epithelial type, two (BWT26 and 30) as the mixed type and one (BWT27) as the mesenchymal type. While the mesenchymal and mixed types were found in both WT1-mutant and WT1-wild-type bilateral WTs, the epithelial type was only found in WT1-wild-type bilateral WTs. Two specimens obtained after chemotherapy showed either the mixed or mesenchymal type. None of the tumour specimens from 31 patients exhibited features of focal or diffuse anaplasia.

The penetrance rates of WTs with inherited or DNWT1 abnormalities, classified according to parental inheritance and WT1 abnormality types. We summarised 22 children from 14 families who inherited WT1 mutation/deletion from their mothers or fathers, and 8 children who had de novo large deletion encompassing WT1 of known parental germ cell origin from the present study and literatures listed in PubMed. The 22 individuals included 3 patients with WTs (FWT4-1, 4-3 and FWT12-1; Figure 1, Table 3); although molecular analyses have not been done in their PB and tumour samples, the pedigrees showed that the 3 patients who developed WT were thought to inherit WT1 mutations/deletions from their father or mother. 

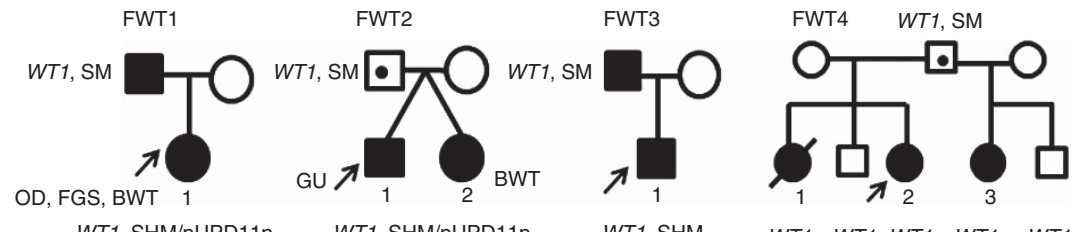

WT1, SHM/pUPD11p WT1, SHM/pUPD11p WT1, SHM

WT1, WT1, WT1, WT1, WT1

NE wt SHM NE NE
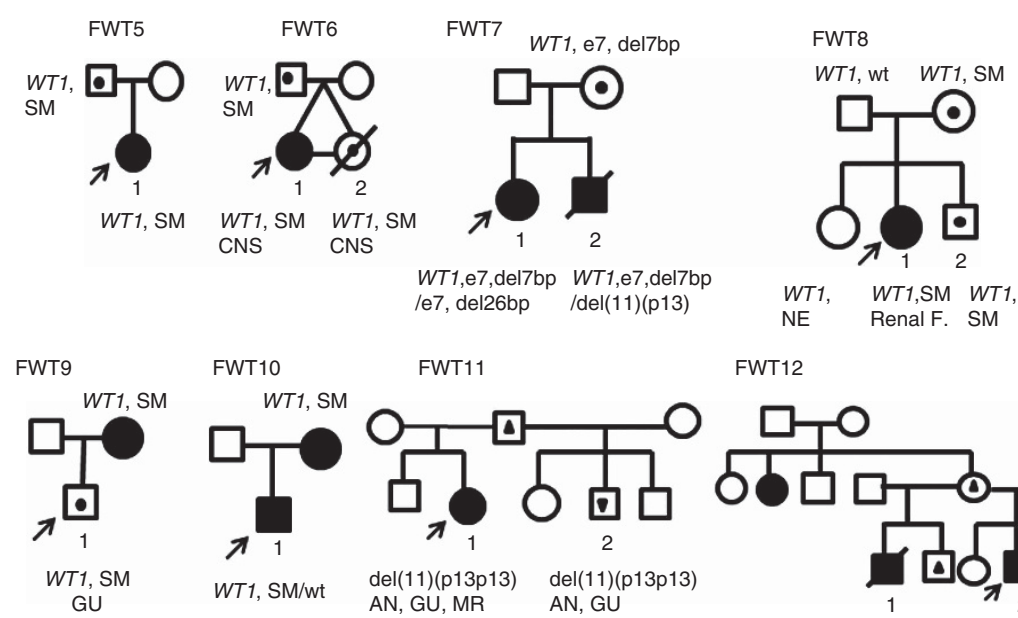

FWT12

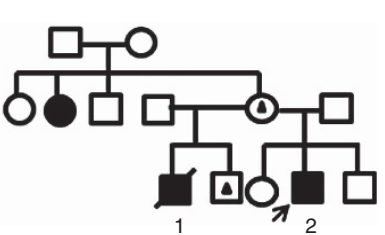

$\begin{array}{ll}W T 1, \mathrm{NE} & \operatorname{del}(11)(\mathrm{p} 13 \mathrm{p} 14) \\ \text { AN, GU, BWT }\end{array}$

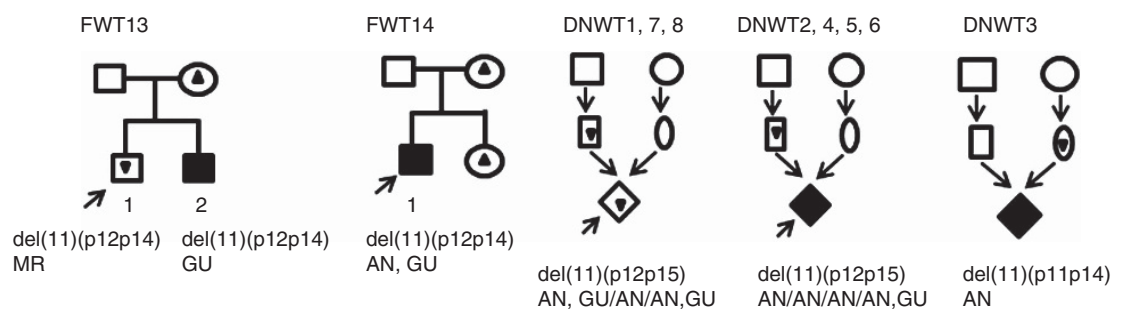

Figure 1. Pedigrees of patients with WTs with small WT1 germline mutations inherited from fathers (FWT1-6) and mothers (FWT7-10), and those of patients with large 11p13 deletions encompassing WT1 inherited from fathers (FWT11) or mothers (FWT12-14). DNWT1-8 indicates eight families having the de novo deletion of paternal or maternal germ cell origin. Open boxes and circles containing a small circle indicate males and females, respectively, with germinal WT1 mutations who did not develop WT. Filled boxes and circles indicate males and females, respectively, who developed WT. WT6-2 was excluded from the penetrance analysis because of the reason described in the text (Fencl et al, 2012). Open boxes and circles with an upright triangle indicate males and females, respectively, with a balanced chromosomal insertion involving the $11 \mathrm{p} 13$ band. Open boxes with an inverted triangle indicate males with the deletion who did not develop WT. Oblongs and ovals indicate paternal and maternal germ cells, respectively. Filled and open diamonds indicate males and females, who developed and did not develop WT, respectively. Abbreviations: $\mathrm{AN}=$ aniridia; $\mathrm{CNS}=$ congenital nephrotic syndrome; $\mathrm{FGS}=$ focal glomerular sclerosis; $\mathrm{GU}=$ genitourinary malformation; $\mathrm{MR}=$ mental retardation; $\mathrm{NE}=$ not examined; renal $\mathrm{F}=$ renal failure; $\mathrm{SM}=$ small mutation; $\mathrm{SHM}=$ small homozygous mutation; wt $=$ wild type.

Identical twins (DNWT9-1,2) in this study shared the same nonsense mutation in PB and tumour samples (Table 3). Because their parents had no WT1 mutation in PB, SNP array analysis was performed on 10 polymorphic markers around $W T 1$ to identify the parental origin of the DNWT1 mutation using PB from the parents and twins as well as tumour samples. Because the maternally derived loci identified by SNP markers (SNP A 1946935, 2241668, 4231943 and seven others) were lost in the tumour with UPD on $11 \mathrm{p}$, the paternal germ cell origin of the mutation was determined (Table 3). In addition, two patients (DNWT10, 11) were reported to have small homozygous WT1 mutations of paternal germ cell origin in tumours (Nordenskjold et al, 1994). These four patients with small DNWT1 mutations of paternal germ cell origin (DNWT9-1, 9-2, 10 and 11) were excluded from the penetrance analysis, because unaffected carriers with small DNWT1 mutations could not be evaluated. In contrast, eight children with large de novo 11p13 deletions (DNWT1-8) were included in the analysis as carriers without development of WT could be evaluated (Figure 1; Huff et al, 1990).
All nine patients who inherited a small WT1 mutation from their fathers developed WT; a girl (FWT6-2) was excluded from the penetrance analysis because she died of renal failure at the age of 23 weeks before the possible development of WT (Pelletier et al, 1991; Kaplinsky et al, 1996; Jeanpierre et al, 1998; Shibata et al, 2002; Fencl et al, 2012). Of nine WTs with the paternal inheritance of WT1 mutation, four tumours [FWT1 (BWT23L, 23R), 2-1, 2-2] in this study showed homozygous WT1 mutations and PUPD on 11p, and two (FWT3, 4-2) showed homozygous WT1 mutations, suggesting that the six tumours may have had the same WT1 and IGF2 abnormalities (Figure 1 and Table 3 ).

Of 6 individuals who inherited small WT1 mutations from their mothers, 4 developed WT; in addition to the small germline mutation in 1 allele 1 had a 26 base-pair deletion that differed from the first mutation (FWT7-1), 1 had a large 11p13 deletion (FWT7-2), 1 had a wild-type WT1 (FWT10) in the other allele in their tumours and the WT1 status in the tumour was not examined in the last patient (FWT8-1; Pritchard-Jones et al, 2000; Zirn et al, 2005; Regev et al, 2008; Melchionda et al, 2013). Thus, all three 


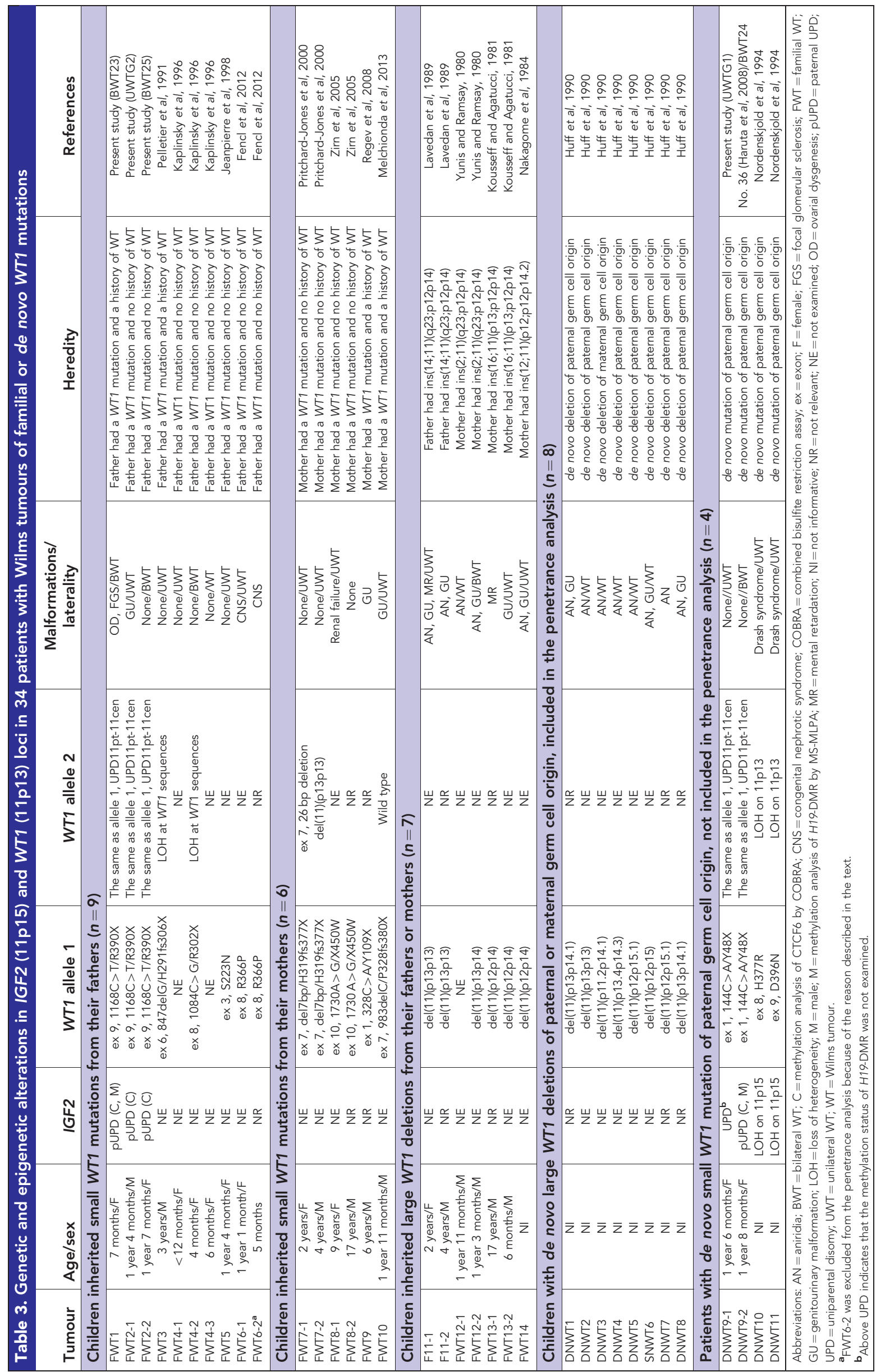


patients who inherited the WT1 mutation from their mothers and whose WT1 status in tumours were examined were not likely to have UPD on $11 \mathrm{p}$ in their tumours (Figure 1 and Table 3 ). The mean ages at diagnosis were 14.2 months for the nine patients with the paternal inheritance and 55.3 months for the four patients with the maternal inheritance; the mean age of the nine patients who inherited the mutations from their fathers was younger than that of the four patients who inherited the mutations from their mothers $(P=0.011$ by Mann-Whitney test).

Fifteen individuals from 12 families were shown to have inherited (FWT11-14) or de novo large 11p13 deletions (DNWT1-8) of paternal or maternal origin (Figure 1 and Table 3; Yunis and Ramsay, 1980; Kousseff and Agatucci, 1981; Nakagome et al, 1984; Lavedan et al, 1989; Huff et al, 1990; Nordenskjold et al, 1994). All four parents who transmitted large $11 \mathrm{p} 13$ deletions had balanced chromosomal insertions involving the $11 \mathrm{p} 13$ band. Ten patients developed WTs, on which sequencing analysis of WT1 was not conducted to identify the status of the other WT1 allele in the tumours. Thus, the penetrance rate was $100 \%$ (9/9) for individuals who inherited small WT1 mutations from their fathers, and was $67 \%(14 / 21)$ for individuals who inherited small WT1 mutations from their mothers or large $11 \mathrm{p} 13$ deletions or had de novo large $11 \mathrm{p} 13$ deletions irrespective of the parental origin. Thus, the 9 individuals were more likely to develop WT than the 21 individuals $(P=0.057)$.

\section{DISCUSSION}

The incidence of WT1 abnormalities in the bilateral WTs of Japanese children was $81 \%$, and this incidence was markedly higher than those reported in American, UK and Australian children (the mean percentage of three series, $32 \% ; P=9.4 \mathrm{E}-05$; Table 4; Huff, 1998; Scott et al, 2012; Hu et al, 2013). The present series included 31 patients and 45 bilateral WTs, and the UK series included 11 patients and 11 bilateral WTs; the statuses of WT1 and 11 p15 were precisely examined in 44 of the 45 and all 11 tumours (Table 4; Scott et al, 2012). The incidence of WT1 abnormality is more frequent in Japanese tumours than in British tumours; however, if we consider that the incidence of WT among Japanese is half of that in Caucasians, the population-based rate of bilateral WT with WT1 abnormality may be similar between the two populations (Figure 2). Diller et al (1998) found constitutional WT1 abnormalities in 8 of 157 (5\%) American children with a history of WT. Likewise, Little et al (2004) found constitutional WT1 abnormalities in $6(2 \%)$ of 282 British children with nonsyndromic WT. Unfortunately, no studies on constitutional WT1 abnormalities have been performed in Japanese children with WT that precluded the comparison of the incidence of constitutional WT1 abnormalities between the two ethnic populations.
In contrast to the equivocal findings in the incidence of WT1 abnormality, that of IGF2 LOI was clearly higher in British children with WT1-wild-type or WT1-wild-type plus WT1-mutant bilateral WT than Japanese counterparts (Table 4 and Figure 2; Scott et al, 2012). Thus, it is clear that the incidence of IGF2 LOI in Caucasian bilateral WTs is higher than that in Japanese counterparts, and that the incidence of WT1 wild-type was low in Japanese bilateral WTs.

The incidence rates of WT are known to vary, being markedly lower in East Asian children than in their Caucasian counterparts (Parkin et al, 1988). We previously reported that if only sporadic WTs were included, the frequencies of WT with WT1 abnormality were similar between East-Asian and Caucasian populations (Haruta et al, 2012). Furthermore, we reported a lower incidence of WT with IGF2 LOI in Japanese children than in American children $(P=0.041)$, and we and others proposed that the lower incidence of IGF2 LOI may be one of the reasons for the lower incidence of WT in Japan (Fukuzawa et al, 2004; Haruta et al, 2012). Contrary to the equivocal findings in the incidences of WT1 abnormality in sporadic or bilateral WTs between the two populations, the difference in the incidence of IGF2 LOI in bilateral WTs is clear $(P=0.036)$; the relationship is comparative to that of IGF2 LOI in sporadic WTs between the two populations. Beckwith-Wiedemann syndrome is an imprinting-related growth disorder. Five to $10 \%$ of patients with BWS have methylation of H19-DMR on both parental chromosomes, resulting in IGF2 LOI (Cerrato et al, 2008). Interestingly, Japanese patients with BWS were shown to have a significantly lower frequency of H19-DMR hypermethylation than North American and European patients, whereas the incidences of pUPD on 11 p15 were comparable, suggesting that susceptibility to epigenetic alterations differs between the two populations (Sasaki et al, 2007). The constitutional 11p15 abnormalities in patients with WT were reported from UK and Netherlands. The UK series included 437 patients with non-syndromic WT and found 11p15 abnormalities in 13 (3\%) patients; of the 13 patients 4 had bilateral WT and 6 had hypermethylation of H19-DMR (Scott et al, 2008). The Netherlands series included 109 patients with syndromic or non-syndromic WTs and found $8(7.3 \%)$ children with $11 \mathrm{p} 15$ abnormalities; of the 8 patients 3 had bilateral WT, 4 had BWS and 3 had hypermethylation of H19-DMR (Segers et al, 2012). Of 13 patients whose methylation status of H19-DMR in PB was examined in the present series, all including 1 (BWT29) with IGF2 LOI in the tumour showed the normal methylation pattern. Thus, the involvement of the constitutional IGF2 LOI in Japanese bilateral WTs could not be identified. The same decreased susceptibility to the epigenetic change reported in BWS may have also caused the decreased incidence of bilateral WTs with IGF2 LOI (Sasaki et al, 2007). The study for constitutional 11p15 abnormalities in Japanese WTs is needed to prove the hypothesis.

Table 4. Incidence rates of WT1 and IGF2 abnormalities in Japanese and British, American or Australian series of bilateral Wilms tumour

\begin{tabular}{|c|c|c|c|c|c|c|c|c|c|c|c|c|}
\hline & WT1 $a b n+w t$ & pUPD & ROI & LOI & WT1 abn & pUPD & ROI & LOI & WT1 wt & pUPD & ROI & LOI \\
\hline A. Japan (the present study) & $45^{a}(31)$ & $34^{a}$ & 8 & 3 & $35^{\mathrm{a}}(25)$ & $31^{a}$ & 4 & 0 & $10(6)$ & 3 & 4 & 3 \\
\hline $\begin{array}{l}\text { B. UK (Scott et al, 2012) } \\
\text { Constitutional defect-associated } \\
\text { Sporadic }\end{array}$ & $\begin{array}{c}11 \\
5 \\
6\end{array}$ & $\begin{array}{l}5 \\
5 \\
0\end{array}$ & $\begin{array}{l}0 \\
0 \\
0\end{array}$ & $\begin{array}{l}6 \\
0 \\
6\end{array}$ & $\begin{array}{l}4 \\
4 \\
0\end{array}$ & $\begin{array}{l}4 \\
4 \\
0\end{array}$ & $\begin{array}{l}0 \\
0 \\
0\end{array}$ & $\begin{array}{l}0 \\
0 \\
0\end{array}$ & $\begin{array}{l}7 \\
1 \\
6\end{array}$ & $\begin{array}{l}1 \\
1 \\
0\end{array}$ & $\begin{array}{l}0 \\
0 \\
0\end{array}$ & $\begin{array}{l}6 \\
0 \\
6\end{array}$ \\
\hline C. USA (Huff, 1998) & 15 & NE & NE & $\mathrm{NE}$ & 4 & NE & $\mathrm{NE}$ & NE & 11 & NE & $\mathrm{NE}$ & NE \\
\hline D. Australia (Hu et al, 2013) & 8 & NE & $\mathrm{NE}$ & $\mathrm{NE}$ & 3 & NE & NE & $\mathrm{NE}$ & 5 & NE & $\mathrm{NE}$ & NE \\
\hline \multicolumn{13}{|c|}{ 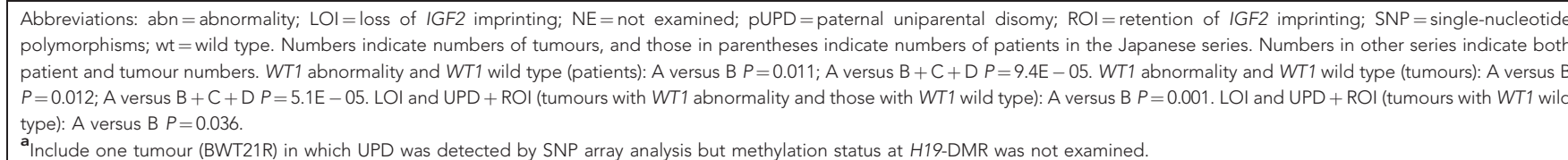 } \\
\hline
\end{tabular}


The present study included six patients having bilateral WTs with wild-type $W T 1$, and one of them had PCS syndrome, which was caused by a $B U B 1 B$ mutation and known to be associated with

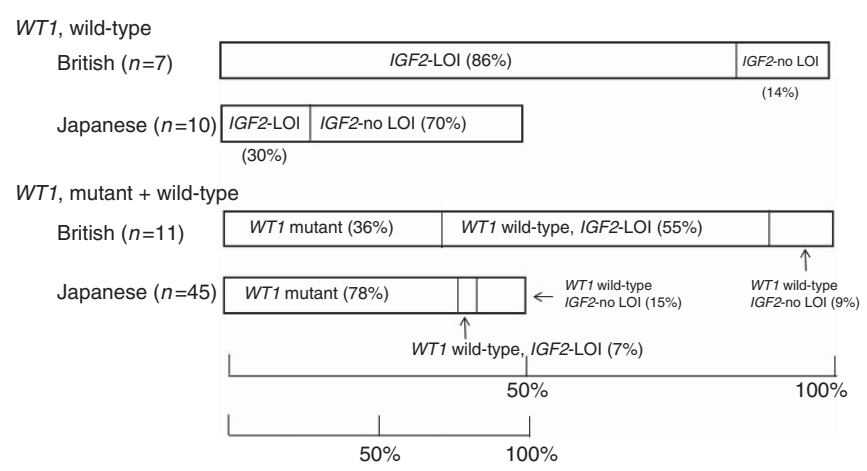

Figure 2. Abnormalities of the WT1 and IGF2-LOI in bilateral WTs in Japanese (the present series) and British children (Scott et al, 2012). The bar length for Japanese is half of that for Caucasians because the incidence rate for Japanese is half of that for Caucasians. a predisposition to WT (Matsuura et al, 2006). The FWT genes, FWT1 and FWT2, were located at $17 \mathrm{q} 21$ and $19 \mathrm{q} 13$, respectively, and the lack of a linkage to these loci in some WT families was reported previously and indicated the existence of additional FWT genes (Ruteshouser and Huff, 2004). Very recently, Hanks et al (2014) identified germline mutation of the CTR9 gene in 3 of 35 WT families using an exome and sequencing analysis and proposed it as a new WT predisposing gene. These genes may be candidates for germline mutations in the other five patients with WT1-wild-type bilateral WTs in the present series.

A previous study showed that the WT1 mutations observed in bilateral WT were of germline origin (Huff, 1998). Another study reviewed WT1 germline mutations in 117 patients with WTs (Royer-Pokora et al, 2004). Of the 117 patients, 44 had bilateral WT, indicating that a large proportion of germline WT1 mutations are associated with bilateral WT, although the inheritance is not known in all patients. The present study included 25 patients with WT1-mutant bilateral WTs, and the status of WT1 in PB was only examined in 3 patients and 6 parents from 3 families; 2 were shown to have inherited the mutation from their father with or without a past history of WT and 1 was identified to have a DNWT1 mutation of paternal germ cell origin. Thus, mutation analyses of

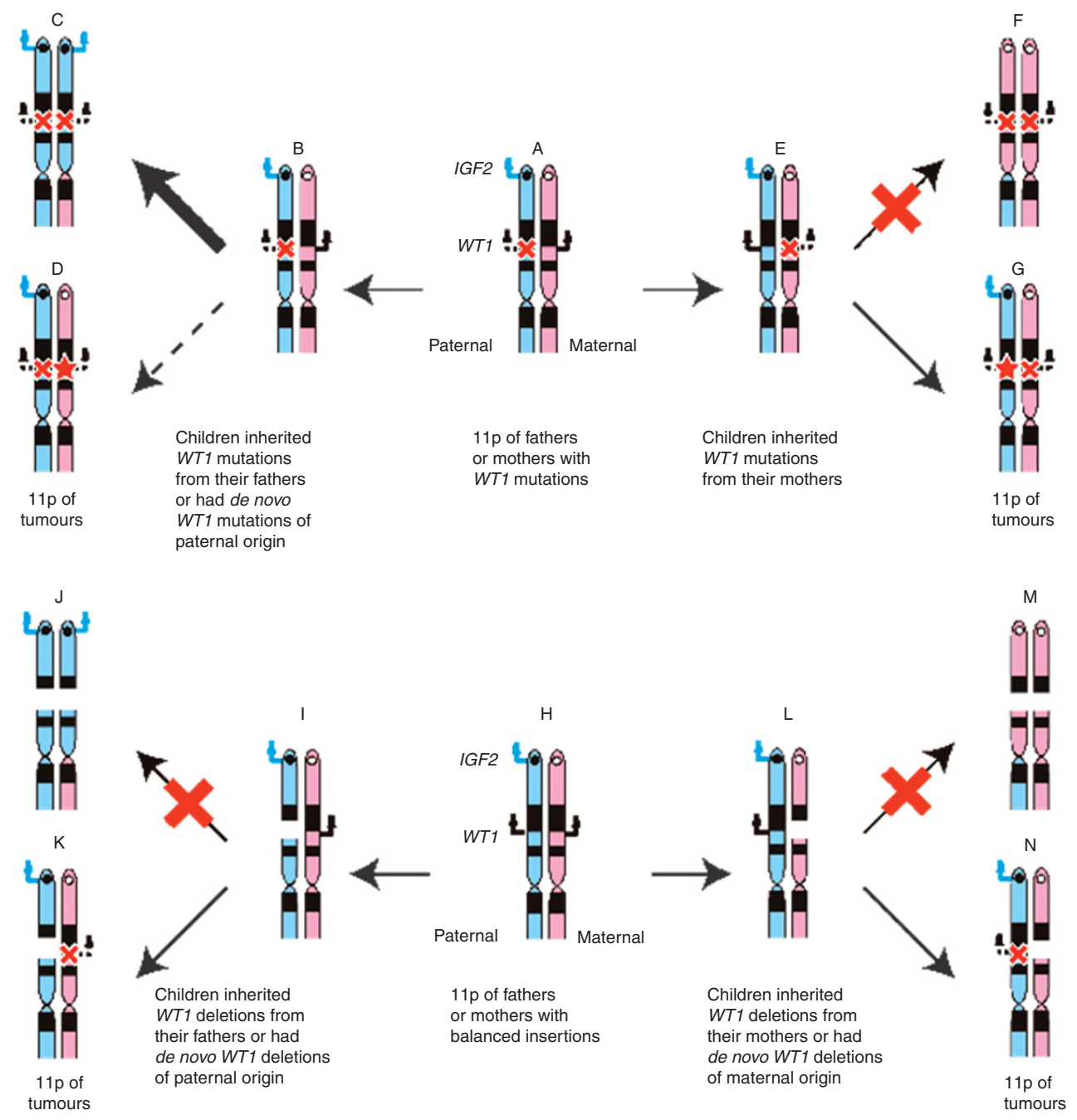

Figure 3. Parental inheritance of small WT1 mutations and large 11 p13 deletion and a model of Wilms tumorigenesis. Black and white circles in terminal 11 p represent methylated and unmethylated statuses, respectively, at CTCF6 in the IGF2-H19 region. Blue arrows indicate the expression of IGF2. $\times$ and star in the 11 p13 region indicate the first and second WT1 mutations, respectively. Solid and broken arrows in the 11 p13 region indicate normal and abnormal WT1 expression, respectively. Parents had balanced insertions involving the $11 \mathrm{p} 13$ band $(\mathbf{H})$. A gap in the $11 \mathrm{p}$ chromatid ( $\mathbf{I}$ and $\mathbf{L}$ ) indicates a large deletion encompassing $\mathbf{W T 1}$, and $\times$ in the 11p13 region indicates the second WT1 mutations (K and $\mathbf{N})$. Explanation for panels $\mathbf{A}-\mathbf{G}, \mathbf{J}$, and $\mathbf{M}$ is described in the discussion. 
WT1 in the PB of patients and their parents are needed to determine whether the mutation is inherited from the parents or occurred de novo.

A previous study examined the parental origin of de novo $R B 1$ mutations, and found the paternal origin of the mutation in all patients (Dryja et al, 1989). Regarding DNWT1 alterations, we and other researchers found the paternal germ cell origin of the small mutation in four patients and that of the large deletion in seven patients and the maternal germ cell origin of the large deletion in one patient (Huff et al, 1990; Nordenskjold et al, 1994). No studies have reported the maternal germ cell origin of de novo small WT1 mutations. In a review on human germinal mutations, Crow (2000) described that one marked difference between the human male and female was that there are many more germline cell divisions in the life history of a sperm than that of an egg. In WTs with homozygous WT1 mutations and paternal IGF2 UPD, the IGF2 alteration is thought to be the second genetic event subsequent to the WT1 alteration that has been shown to occur in the paternal WT1 allele. The result that pUPD on 11p was found in the great majority of bilateral WTs in the present study further supports the paternal germ cell origin of de novo small WT1 mutations.

We summarised the data of all 30 children from 22 families with hereditary WT, whose inheritance of the WT1 alteration was described in the present and previous studies (Table 3; Yunis and Ramsay, 1980; Kousseff and Agatucci, 1981; Nakagome et al, 1984; Lavedan et al, 1989; Pelletier et al, 1991; Kaplinsky et al, 1996; Jeanpierre et al, 1998; Pritchard-Jones et al, 2000; Shibata et al, 2002; Zirn et al, 2005; Regev et al, 2008; Fencl et al, 2012; Melchionda et al, 2013). We classified 30 children into 3 groups based on parental inheritance of the germline mutation and types of WT1 abnormality, and found that children who inherited small WT1 mutations from their father were more likely to have the higher penetrance rate than those who inherited small WT1 mutations from their mothers or inherited the large deletions or had the de novo large deletions irrespective of parental origin $(P=0.057$; Figure 1$)$. Why do parental inheritance and WT1 abnormality types affect the penetrance rate? Most parents had DNWT1 mutations of paternal germ cell origin, as shown in (Figure 3A). Children who had a small WT1 mutation of paternal germ cell origin easily developed WT because pUPD on 11p resulted in homozygous WT1 mutations and simultaneous overexpression of IGF2 (Figure 3B and C). Children less frequently developed WT by the second mutation in the maternally derived WT1 allele because this tumorigenic pathway needs additional genetic and/or epigenetic events (Figure 3D). In contrast, WTs developed in children who inherited the small mutation from their mothers could not take advantage of simultaneous alterations in WT1 and IGF2 because maternally derived IGF2 is imprinted and repressed (Figure $3 \mathrm{E}$ and F). Children who inherited the small mutations from their mothers could develop WT if an independent $W T 1$ mutation occurred in the paternally derived $W T 1$ allele, which resides on the same 11p expressing IGF2; expression even from one IGF2 allele may be important for the development of embryonic tumours (Figure 3G).

Regarding the large $11 \mathrm{p} 13$ deletion, children who inherited the large deletions or had the de novo large deletions could develop WT if an independent WT1 mutation occurred in the paternally or maternally derived WT1 allele (Figure $3 \mathrm{~K}$ and N). However, large homozygous deletions in the $11 \mathrm{p} 13$ chromosomal region caused by UPD on $11 p$ were unlikely to occur in a nephroblast, because of disadvantage for survival with the loss of a large number of genes (Figure $3 \mathrm{~J}$ and $\mathrm{M}$ ). In fact, seven tumours developed in patients with WAGR syndrome, in which both WT1 and IGF2 statuses were examined, showed large $11 \mathrm{p} 13$ deletions in one WT1 allele and small mutations in the other allele and $\mathrm{ROH}$ on 11pter-11p13 (BWT2L, BWT2R and UWTG6-10; Tables 1 and 2). Furthermore, the patients inherited the small mutations from their fathers were younger than those who inherited the small mutations from their mothers, and the patients with a sporadic and UWT with small homozygous WT1 mutations and pUPD of IGF2 were younger than those with a sporadic and UWT with the large deletion. These findings indicate that a small WT1 mutation with pUPD on $11 \mathrm{p}$ is the most efficient mechanism for WT development.

The present result on the WT1 and IGF2 statuses in bilateral and FWT led to the hypothesis that individuals who inherited small WT1 mutations from their fathers may be more likely to develop WT than those who inherited the small mutations from their mothers or inherited large $11 \mathrm{p} 13$ deletions or had the de novo large deletions irrespective of parental origin. It is obvious that genetic and epigenetic studies in a large number of WT families with WT1 mutations are needed to confirm the hypothesis. We believe that if confirmed the present findings are useful for the genetic counselling of individuals, including WT survivors, who may inherit WT1 mutations.

\section{ACKNOWLEDGEMENTS}

We thank the patients, parents and physicians who participated in the study of the Japan Wilms Tumor Study Group. Grants-in-Aid for scientific research (nos. 2039045, 2339045, and 80392190) from the Japanese Ministry of Education, Culture, Sports, Science and Technology (YK; HO; MH; TO; SH; TK and MF), Health and Labor Sciences Research Grants, Research for Promotion of Cancer Central (26273001) (YK; TO; TK; MF), and the Kawano Masanori Memorial Foundation for Promotion of Pediatrics (MH).

\section{CONFLICT OF INTEREST}

The authors declare no conflict of interest.

\section{AUTHORS CONTRIBUTIONS}

YK, HO, TO, SH and MF designed the research; TK, AY, YO and TT participated in data collection and interpretation; $\mathrm{HO}, \mathrm{MH}$, $\mathrm{YA}, \mathrm{YT}$ and $\mathrm{HH}$ participated in the molecular and pathological analysis; YK drafted the manuscript.

\section{REFERENCES}

Cerrato F, Sparago A, Verde G, De Crescenzo A, Citro V, Cubellis MV, Rinaldi MM, Boccuto L, Neri G, Magnani C, D’Angelo P, Collini P, Perotti D, Sebastio G, Maher ER, Riccio A (2008) Different mechanisms cause imprinting defects at the IGF2/H19 locus in Beckwith-Wiedemann syndrome and Wilms' tumour. Hum Mol Genet 17(10): 1427-1435.

Crow JF (2000) The origins, patterns and implications of human spontaneous mutation. Nat Rev Genet 1(1): 40-47.

D’Angio GJ, Breslow N, Beckwith JB, Evans A, Baum H, deLorimier A, Fernbach D, Hrabovsky E, Jones B, Kelalis P, Othersen HB, Tefft M, Thomas PRM (1989) Treatment of Wilms' tumor. Results of the third national Wilms' tumor Study. Cancer 64(2): 349-360.

Diller L, Ghahremani M, Morgan J, Grundy P, Reeves C, Breslow N, Green D, Neuberg D, Pelletier J, Li FP (1998) Constitutional WT1 mutations in Wilms' tumor patients. J Clin Oncol 16(11): 3634-3640.

Dryja TP, Mukai S, Petersen R, Rapaport JM, Walton D, Yandell DW (1989) Parental origin of mutations of the retinoblastoma gene. Nature 339(6225): 556-558.

Fencl F, Malina M, Stara V, Zieg J, Mixova D, Seeman T, Blahova K (2012) Discordant expression of a new WT1 gene mutation in a family with monozygotic twins presenting with congenital nephrotic syndrome. Eur J Pediatr 171(1): 121-124. 
Foulstone E, Prince S, Zaccheo O, Burns JL, Harper J, Jacobs C, Church D, Hassan AB (2005) Insulin-like growth factor ligands, receptors, and binding proteins in cancer. J Pathol 205(2): 145-153.

Fukuzawa R, Breslow NE, Morison IM, Dwyer P, Kusafuka T, Kobayashi Y, Becroft DM, Beckwith JB, Perlman EJ, Reeve AE (2004) Epigenetic differences between Wilms' tumours in white and east-Asian children. Lancet 363(9407): 446-451.

Hanks S, Perdeaux ER, Seal S, Ruark E, Mahamdallie SS, Murray A, Ramsay E, Del Vecchio Duarte S, Zachariou A, de Souza B, Warren-Perry M, Elliott A, Davidson A, Price H, Stiller C, Pritchard-Jones K, Rahman N (2014) Germline mutations in the PAF1 complex gene CTR9 predispose to Wilms tumour. Nat Commun 5: 4398.

Haruta M, Arai Y, Sugawara W, Watanabe N, Honda S, Ohshima J, Soejima H, Nakadate H, Okita H, Hata J, Fukuzawa M, Kaneko Y (2008) Duplication of paternal IGF2 or loss of maternal IGF2 imprinting occurs in half of Wilms tumors with various structural WT1 abnormalities. Genes Chromosomes Cancer 47(8): 712-727.

Haruta M, Arai Y, Watanabe N, Fujiwara Y, Honda S, Ohshima J, Kasai F, Nakadate H, Horie H, Okita H, Hata J, Fukuzawa M, Kaneko Y (2012) Different incidences of epigenetic but not genetic abnormalities between Wilms tumors in Japanese and Caucasian children. Cancer Sci 103(6): 1129-1135.

Hu M, Fletcher J, McCahon E, Catchpoole D, Zhang GY, Wang YM, Algar EM, Alexander SI (2013) Bilateral Wilms tumor and early presentation in pediatric patients is associated with the truncation of the Wilms tumor 1 protein. J Pediatr 163(1): 224-229.

Hu Q, Gao F, Tian W, Ruteshouser EC, Wang Y, Lazar A, Stewart J, Strong LC, Behringer RR, Huff V (2011) Wt1 ablation and Igf2 upregulation in mice result in Wilms tumors with elevated ERK1/2 phosphorylation. J Clin Invest 121(1): 174-183.

Huff V (1998) Wilms tumor genetics. Am J Med Genet 79(4): 260-267.

Huff V (2011) Wilms' tumours: about tumour suppressor genes, an oncogene and a chameleon gene. Nat Rev Cancer 11(2): 111-121.

Huff V, Meadows A, Riccardi VM, Strong LC, Saunders GF (1990) Parental origin of de novo constitutional deletions of chromosomal band 11p13. Am J Hum Genet 47(1): 155-160.

Jeanpierre C, Denamur E, Henry I, Cabanis MO, Luce S, Cecille A, Elion J, Peuchmaur M, Loirat C, Niaudet P, Gubler MC, Junien C (1998) Identification of constitutional WT1 mutations, in patients with isolated diffuse mesangial sclerosis, and analysis of genotype/phenotype correlations by use of a computerized mutation database. Am J Hum Genet 62(4): 824-833.

Kaplinsky C, Ghahremani M, Frishberg Y, Rechavi G, Pelletier J (1996) Familial Wilms' tumor associated with a WT1 zinc finger mutation. Genomics 38(3): 451-453.

Kousseff BG, Agatucci A (1981) Aniridia-Wilms tumor association. J Pediatr 98(4): 676-678.

Lavedan C, Barichard F, Azoulay M, Couillin P, Molina Gomez D, Nicolas H, Quack B, Rethore MO, Noel B, Junien C (1989) Molecular definition of de novo and genetically transmitted WAGR-associated rearrangements of 11p13. Cytogenet Cell Genet 50(2-3): 70-74.

Leiderman YI, Kiss S, Mukai S (2007) Molecular genetics of RB1-the retinoblastoma gene. Semin Ophthalmol 22(4): 247-254.

Little MH, Dunn R, Byrne JA, Seawright A, Smith PJ, Pritchard-Jones K, van Heyningen V, Hastie ND (1992) Equivalent expression of paternally and maternally inherited WT1 alleles in normal fetal tissue and Wilms' tumours. Oncogene 7(4): 635-641.

Little SE, Hanks SP, King-Underwood L, Jones C, Rapley EA, Rahman N, Pritchard-Jones K (2004) Frequency and heritability of WT1 mutations in nonsyndromic Wilms' tumor patients: a UK Children's Cancer Study Group Study. J Clin Oncol 22(20): 4140-4146.

Matsuura S, Matsumoto Y, Morishima K, Izumi H, Matsumoto H, Ito E, Tsutsui K, Kobayashi J, Tauchi H, Kajiwara Y, Hama S, Kurisu K, Tahara H, Oshimura M, Komatsu K, Ikeuchi T, Kajii T (2006) Monoallelic $B U B 1 B$ mutations and defective mitotic-spindle checkpoint in seven families with premature chromatid separation (PCS) syndrome. Am J Med Genet A 140(4): 358-367.

Melchionda F, Spreafico F, Ciceri S, Lima M, Collini P, Pession A, Massimino M, Radice P, Perotti D (2013) A novel WT1 mutation in familial Wilms tumor. Pediatr Blood Cancer 60(8): 1388-1389.

Nakagome Y, Ise T, Sakurai M, Nakajo T, Okamoto E, Takano T, Nakahori Y, Tsuchida Y, Nagahara N, Takada Y, Ohsawa Y, Sawaguchi S, Toyosaka A, Kobayashi N, Matsunaga E, Saito S (1984) High-resolution studies in patients with aniridia-Wilms tumor association, Wilms tumor or related congenital abnormalities. Hum Genet 67(3): 245-248.
Nannya Y, Sanada M, Nakazaki K, Hosoya N, Wang L, Hangaishi A, Kurokawa M, Chiba S, Bailey DK, Kennedy GC, Ogawa S (2005) A robust algorithm for copy number detection using high-density oligonucleotide single nucleotide polymorphism genotyping arrays. Cancer Res 65(14): 6071-6079.

Nordenskjold A, Friedman E, Anvret M (1994) WT1 mutations in patients with Denys-Drash syndrome: a novel mutation in exon 8 and paternal allele origin. Hum Genet 93(2): 115-120.

Oue T, Fukuzawa M, Okita H, Mugishima H, Horie H, Hata J, Saito M, Nozaki M, Chin M, Nakadate H, Hinotsu S, Koshinaga T, Kaneko Y, Kitano Y, Tanaka Y (2009) Outcome of pediatric renal tumor treated using the Japan Wilms Tumor Study-1 (JWiTS-1) protocol: a report from the JWiTS group. Pediatr Surg Int 25(11): 923-929.

Parkin DM, Stiller CA, Draper GJ, Bieber CA (1988) The international incidence of childhood cancer. Int J Cancer 42(4): 511-520.

Pelletier J, Bruening W, Li FP, Haber DA, Glaser T, Housman DE (1991) WT1 mutations contribute to abnormal genital system development and hereditary Wilms' tumour. Nature 353(6343): 431-434.

Pritchard-Jones K, Rahman N, Gerrard M, Variend D, King-Underwood L (2000) Familial Wilms tumour resulting from WT1 mutation: intronic polymorphism causing artefactual constitutional homozygosity. J Med Genet 37(5): 377-379.

Ravenel JD, Broman KW, Perlman EJ, Niemitz EL, Jayawardena TM, Bell DW, Haber DA, Uejima H, Feinberg AP (2001) Loss of imprinting of insulin-like growth factor-II (IGF2) gene in distinguishing specific biologic subtypes of Wilms tumor. J Natl Cancer Inst 93(22): 1698-1703.

Regev M, Kirk R, Mashevich M, Bistritzer Z, Reish O (2008) Vertical transmission of a mutation in exon 1 of the WT1 gene: lessons for genetic counseling. Am J Med Genet A 146A(18): 2332-2336.

Rivera MN, Haber DA (2005) Wilms' tumour: connecting tumorigenesis and organ development in the kidney. Nat Rev Cancer 5(9): 699-712.

Royer-Pokora B, Beier M, Henzler M, Alam R, Schumacher V, Weirich A, Huff V (2004) Twenty-four new cases of WT1 germline mutations and review of the literature: genotype/phenotype correlations for Wilms tumor development. Am J Med Genet A 127A(3): 249-257.

Royer-Pokora B, Weirich A, Schumacher V, Uschkereit C, Beier M, Leuschner I, Graf N, Autschbach F, Schneider D, von Harrach M (2008) Clinical relevance of mutations in the Wilms tumor suppressor 1 gene WT1 and the cadherin-associated protein betal gene CTNNB1 for patients with Wilms tumors: results of long-term surveillance of 71 patients from International Society of Pediatric Oncology Study 9/Society for Pediatric Oncology. Cancer 113(5): 1080-1089.

Ruteshouser EC, Huff V (2004) Familial Wilms tumor. Am J Med Genet C Semin Med Genet 129C(1): 29-34.

Sasaki K, Soejima H, Higashimoto K, Yatsuki H, Ohashi H, Yakabe S, Joh K, Niikawa N, Mukai T (2007) Japanese and North American/European patients with Beckwith-Wiedemann syndrome have different frequencies of some epigenetic and genetic alterations. Eur J Hum Genet 15(12): 1205-1210.

Schroeder WT, Chao LY, Dao DD, Strong LC, Pathak S, Riccardi V, Lewis WH, Saunders GF (1987) Nonrandom loss of maternal chromosome 11 alleles in Wilms tumors. Am J Hum Genet 40(5): 413-420.

Scott RH, Douglas J, Baskcomb L, Huxter N, Barker K, Hanks S, Craft A, Gerrard M, Kohler JA, Levitt GA, Picton S, Pizer B, Ronghe MD, Williams D, Cook JA, Pujol P, Maher ER, Birch JM, Stiller CA, Pritchard-Jones K, Rahman N (2008) Constitutional 11p15 abnormalities, including heritable imprinting center mutations, cause nonsyndromic Wilms tumor. Nat Genet 40(11): 1329-1334.

Scott RH, Murray A, Baskcomb L, Turnbull C, Loveday C, Al-Saadi R, Williams R, Breatnach F, Gerrard M, Hale J, Kohler J, Lapunzina P, Levitt GA, Picton S, Pizer B, Ronghe MD, Traunecker H, Williams D, Kelsey A, Vujanic GM, Sebire NJ, Grundy P, Stiller CA, Pritchard-Jones K, Douglas J, Rahman N (2012) Stratification of Wilms tumor by genetic and epigenetic analysis. Oncotarget 3(3): 327-335.

Segers H, Kersseboom R, Alders M, Pieters R, Wagner A, van den Heuvel-Eibrink MM (2012) Frequency of WT1 and 11p15 constitutional aberrations and phenotypic correlation in childhood Wilms tumour patients. Eur J Cancer 48(17): 3249-3256.

Shibata R, Hashiguchi A, Sakamoto J, Yamada T, Umezawa A, Hata J (2002) Correlation between a specific Wilms tumour suppressor gene (WT1) mutation and the histological findings in Wilms tumour (WT). J Med Genet 39(12): e83.

The committee on histological classification of childhood tumors. The Japanese Society of Pathology (2008) Tumors of the Kidney, 1st edn. Kanahara Shuppan: Tokyo, Japan. 
Watanabe N, Nakadate H, Haruta M, Sugawara W, Sasaki F, Tsunematsu Y, Kikuta A, Fukuzawa M, Okita H, Hata J, Soejima H, Kaneko Y (2006) Association of $11 \mathrm{q}$ loss, trisomy 12 , and possible $16 \mathrm{q}$ loss with loss of imprinting of insulin-like growth factor-II in Wilms tumor. Genes Chromosomes Cancer 45(6): 592-601.

Yamamoto G, Nannya Y, Kato M, Sanada M, Levine RL, Kawamata N, Hangaishi A, Kurokawa M, Chiba S, Gilliland DG, Koeffler HP, Ogawa S (2007) Highly sensitive method for genomewide detection of allelic composition in nonpaired, primary tumor specimens by use of affymetrix single-nucleotide-polymorphism genotyping microarrays. Am J Hum Genet 81(1): 114-126.
Yunis JJ, Ramsay NK (1980) Familial occurrence of the aniridia-Wilms tumor syndrome with deletion 11p13-14.1. J Pediatr 96(6): 1027-1030.

Zirn B, Wittmann S, Gessler M (2005) Novel familial WT1 read-through mutation associated with Wilms tumor and slow progressive nephropathy. Am J Kidney Dis 45(6): 1100-1104.

This work is published under the standard license to publish agreement. After 12 months the work will become freely available and the license terms will switch to a Creative Commons AttributionNonCommercial-Share Alike 4.0 Unported License. 